2002s-82

\title{
Species Preservation and Biodiversity Value: A Real Options Approach
}

\author{
Ilhem Kassar and Pierre Lasserre
}

\section{Série Scientifique \\ Scientific Series}

\section{Montréal}

Septembre 2002

(C) 2002 Ilhem Kassar and Pierre Lasserre. Tous droits réservés. All rights reserved. Reproduction partielle permise avec citation du document source, incluant la notice (C).

Short sections may be quoted without explicit permission, if full credit, including $@$ notice, is given to the source.
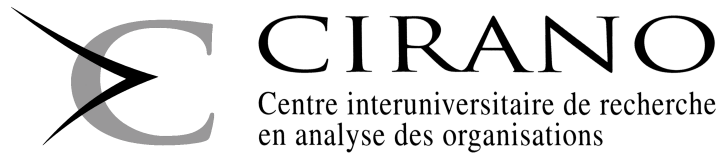

Centre interuniversitaire de recherche en analyse des organisations 


\section{CIRANO}

Le CIRANO est un organisme sans but lucratif constitué en vertu de la Loi des compagnies du Québec. Le financement de son infrastructure et de ses activités de recherche provient des cotisations de ses organisationsmembres, d'une subvention d'infrastructure du ministère de la Recherche, de la Science et de la Technologie, de même que des subventions et mandats obtenus par ses équipes de recherche.

CIRANO is a private non-profit organization incorporated under the Québec Companies Act. Its infrastructure and research activities are funded through fees paid by member organizations, an infrastructure grant from the Ministère de la Recherche, de la Science et de la Technologie, and grants and research mandates obtained by its research teams.

\section{Les organisations-partenaires / The Partner Organizations}

-École des Hautes Études Commerciales

-École Polytechnique de Montréal

-Université Concordia

-Université de Montréal

-Université du Québec à Montréal

-Université Laval

-Université McGill

-Ministère des Finances du Québec

-MRST

-Alcan inc.

- AXA Canada

-Banque du Canada

-Banque Laurentienne du Canada

- Banque Nationale du Canada

- Banque Royale du Canada

-Bell Canada

-Bombardier

-Bourse de Montréal

-Développement des ressources humaines Canada (DRHC)

-Fédération des caisses Desjardins du Québec

-Hydro-Québec

-Industrie Canada

-Pratt \& Whitney Canada Inc.

-Raymond Chabot Grant Thornton

-Ville de Montréal

Les cahiers de la série scientifique (CS) visent à rendre accessibles des résultats de recherche effectuée au CIRANO afin de susciter échanges et commentaires. Ces cahiers sont écrits dans le style des publications scientifiques. Les idées et les opinions émises sont sous l'unique responsabilité des auteurs et ne représentent pas nécessairement les positions du CIRANO ou de ses partenaires.

This paper presents research carried out at CIRANO and aims at encouraging discussion and comment.

The observations and viewpoints expressed are the sole responsibility of the authors. They do not necessarily represent positions of CIRANO or its partners.

\section{ISSN 1198-8177}




\title{
Species Preservation and Biodiversity Value: A Real Options Approach*
}

\author{
Ilhem Kassar ${ }^{\dagger}$ and Pierre Lasserre ${ }^{\ddagger}$
}

\begin{abstract}
Résumé / Abstract
Nous étudions la biodiversité dans un cadre d'options réelles où les ressources sont substituables. Comment optimiser les décisions de conservation quand toute perte de biodiversité est irréversible et les valeurs futures incertaines? Nous montrons que la substituabilité, normalement considérée comme réduisant la valeur d'une espèce, est en fait source de valeur. La valeur marginale est décroissante dans Ie nombre d'espèces mais croissante et convexe dans la valeur de l'espèce marginale. Pour un modèle homogène à deux espèces, nous montrons également que la volatilité est un facteur d'augmentation de la valeur de la biodiversité, tandis que la corrélation réduit tant la valeur totale que la valeur marginale des espèces. Ce rôle de la corrélation entre valeur d'une espèce et valeur des autres espèces rappelle celui du Beta des actifs financiers. De même qu'un actif au Beta négatif tire de la valeur du fait qu'il permet de s'assurer contre les fluctuations du marché, une espèce dont la valeur tend à évoluer en sens inverse de celle de l'espèce en exploitation vaut plus du fait qu'elle a plus de chances de se substituer à cette dernière si celle-ci perd de la valeur.

We evaluate biodiversity in a real options framework, when the resources in use are substitutable. We examine optimal conservation decisions given that a biodiversity loss is irreversible and that future use values are uncertain. While species substitutability is generally believed to reduce the value of diversity, we show that the flexibility associated with substitutability is a source of value. Marginal species value is decreasing in the number of species, but rising and convex in the value of the marginal species. As we show in the two-species homogenous model, increased volatility raises biodiversity value, and a positive correlation between species values both reduces the value of the pool of species and the value of biodiversity. The role played by the correlation between the value of a species and the value of other species, is reminiscent of the Beta of a financial asset. Just like an asset with a negative Beta derives additional value by providing insurance against fluctuations in the market portfolio, a species whose value tends to move in the opposite direction as the species in use derives additional value from its higher probability to be available for substitution if the value of the species in use diminishes.
\end{abstract}

Mots clés : Options réelles; valeur d'option; portefeuille biologique; biodiversité; substituabilité; espèces; actifs; valeur marginale.

Keywords: Real options; Option value; Biodiversity; Biological portfolio; Substitutability; Species; Assets; Marginal value.

Codes JEL : D460, D81O, D990; G11O, G120, H410, Q200.

\footnotetext{
* Financial support from the FQRSC funds, the SSRCC, and the RCM2 is gratefully acknowledged.

$\dagger$ CIRANO.

† Département des sciences économiques, Université du Québec à Montréal, CIRANO, CIREQ, and GREQAM. Please address all correspondence to Pierre Lasserre, CIRANO, rue Université, 25 ème étage, Montréal, Québec, H3A 2A5, Canada. Fax : (514) 985-4039 ; Email : lasserre.pierre@uqam.ca.
} 


\section{Contents}

1 Introduction $\quad 1$

2 A general model to evaluate biodiversity 5

3 A simplified two species homogenous model $\quad 8$

3.1 Abandonment rules and dominance changes . . . . . . . . . . . . 11

3.2 The marginal value of biodiversity . . . . . . . . . . . . . . . 14

4 A non-homogenous model: numerical resolution $\quad 16$

4.1 The last surviving species . . . . . . . . . . . . . 17

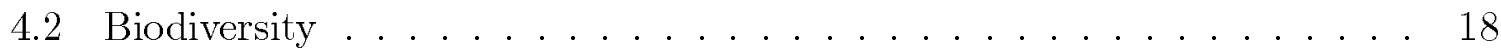

4.3 Uncertainty and value correlation . . . . . . . . . . . 20

5 Discussion and conclusion $\quad 22$ 


\section{Introduction}

Biodiversity is the total variety of life on earth. Biological diversity may also reflect the range of species at a site, the size of the gene pool, or the number of ecosystems on the planet. Extinction is a natural phenomenon that is part of the evolutionary cycle of species. However, by the extension and development of human activity, man's actions have become a cause of natural resources depletion and environment deterioration. Consequently, there is considerable interest in analyzing and assessing the value of biological diversity. In this paper we improve on previous contributions in two ways. First we apply for the first time real options techniques to diversity and marginal diversity, that is to situations where several species interplay, rather than one species only. Second we show that, and explain why, species substitutability may be a source of value for biodiversity, contrary to a widespread belief.

The concept of Total Economic Value, as developed in the literature and adopted by the United Nations (Moran and Bann, 2000), makes a distinction between direct use values (production and consumption), indirect use values (ecosystems stability and survival), existence value (intrinsic value of nature), and option values (potential future uses). Actually any of the first three forms of value may include unknown future components and qualify as option value, the main ingredient to the notion of option value being the irreversibility of a change.

The main focus of the literature on biodiversity valuation is to establish an economic basis for preservation by pointing out to its benefits. Many difficulties arise. Interdependencies between species and their ecological functions within an ecosystem are not well understood (Norton 1988). Existence values are inherent to people's preferences and hence to their willingness to pay (Moran and Bann 2000). With regard to potential use values, option valuation requires the identification of species and their possible uses as well as the assessment of the likelihood of future use discoveries.

Weitzman (1993) shows how diversity theory can be used operationally in the analysis of conservation policies. Using the example of cranes, he defines diversity as a measure 
of genetic differences (distances) between species. The value of marginal diversity is then the value of improving survival probabilities for the different species. Our point of view is related except that the focus is on the survival of the good or service provided by the species rather than the survival of the species itself.

Indeed, as Swanson (1994), we view biological resources as part of the asset portfolio of human society. The decline of a species results from disinvestment, by overexploitation, resource mining, or biodiversity depletion. The real-options approach to biodiversity investments is anterior to this portfolio view; Fisher and Hanemann (1986) proved the existence of a premium from conserving a species or a forest for future use, as long as the future value is uncertain and current exploitation or conversion is irreversible. Regardless of risk preferences there is a flexibility premium in delaying any project that converts a natural environment irreversibly. In a similar real-options context, Wesseler (1999) finds an economic justification to the European Union decision of postponing the release of transgenic crops, as the project has uncertain future direct benefits and uncertain and irreversible costs in terms of biodiversity loss.

Theses approaches to policy or decision making require the quantification of biodiversity value. There is an extensive literature on direct use value, often focusing on research for the development of new marketable products, pharmaceutical products in particular. These studies point to the economic relevance of use value and, hence, of biodiversity. However, as Fromm (2000) shows, the range of valuations and methodologies is quite wide. An important question is substitutability: if a species can be substituted for, it is not unique and it seems natural that its value should be lower than if it was unique.

Simpson et al (1996), and Craft and Simpson (2001), consider substitution possibilities amongst species in a bioprospecting model. A species value depends not only on the probability that it eventually yields a successful commercial product, but also on the likelihood that other species can, or cannot, lead to the development of this product. The value of the marginal species decreases with the number of species and increases

\footnotetext{
${ }^{1}$ Fromm (2000) reports that species values are relatively low when they are based on prospection costs and higher when based on market or social values of eventual products.
} 
with the probability of success. A similar point is made by Fromm (2000) who argues that considering the production value of species reduces the set of species functions to those related to particular uses, thus reducing the value of marginal species. All this results in weak incentives for conservation. Rausser and Small (2000) introduced the concept of information rents in bioprospecting. Given appropriate institutions these rents protect biodiversity. However, here again, the magnitude of the rents depends on the degree of differentiation or substitutability between species.

One major concern of this paper is to check whether production substitutability necessarily reduces grounds for conservation or whether, on the contrary, this might not be a source of value. We consider a pool of species characterized by their ability to produce a specific gene, or a particular principle of interest. All species within that pool are perfectly substitutable in that respect and can contribute to the production of a particular good, a medication for example, or a particular service. Under certainty, since the species are perfect substitutes, only one species, the most convenient one, is needed at any time; all other species in the pool are left unused. This is the situation under which the above literature claims that diversity in the pool is valueless. ${ }^{2}$ The same value is produced if only one species exist as if many do. If conservation is costly, all species will be allowed to disappear except for the most convenient one. Under risk of extinction the conclusion may be diluted somewhat, but not altered in any significant way; close substitutes, often sensitive to similar risks, are not good as insurance policies.

Under uncertainty about the relative abilities of the species in the pool to produce the good or service of interest in the future, the situation is quite different. The species best able to produce the good or service may change over time. If, furthermore, diversity losses are irreversible, then there is a justification for keeping an otherwise useless species alive because it may become the species of choice in the future, despite the fact that it is currently dominated by some other species. In such circumstances, a species that

\footnotetext{
${ }^{2}$ For a dissenting voice, see Dasgupta (2000), who points out that "... to invoke the idea of substitutability among natural resources in order to play down the use value of biodiversity, as people frequently do (e.g., Simon 1981, 1994), is a wrong intellectual move."
} 
would have no use value if it was not a substitute for a valuable species becomes valuable precisely because it is substitutable: our result is not an attenuation of the conventional wisdom on the impact of substitutability on the value of biodiversity; it goes in the opposite direction.

Uncertainty is probably the main issue in valuing biodiversity. In particular, scientific knowledge on relationships and interdependencies among species is in continuous evolution, and future needs or tastes are largely unknown. The model presented in this paper does not claim to be realist, much less to be complete. However there is no doubt that the type of value (use value) and the type of uncertainty (about the relative use values of species) that we introduce are present in most situations involving biodiversity evaluation and decisions. There are clearly other aspects to the evaluation of biodiversity, but the point that we are making is necessarily one of them.

Option values in environmental economics have a history that dates back to Henry (1974), and Arrow and Fisher (1974). Although it has long been clear that losing a species implies losing an option, the innovation in this paper is that we are characterizing an option model involving a relationship between species, rather than a single species. While the model that we are able to solve analytically is restricted to two species and involves special assumptions, its solution is instructive both from an economic and from a methodological point of view. In fact the solution to the more general version of the model that we solve numerically retains several features of the analytical solution. In particular the decision rule whether to conserve a species or allow it to disappear does not involve a critical value of the species but a critical locus that depends on the other species. A species will only be allowed to disappear if it is not likely that it will soon become the dominant species; this depends on how close it is to the other species and, in general, the relative position of the species changes over time.

In the next section we specify a general framework for a real options model of biodiversity evaluation. Simplifying assumptions are made and a model is developed and resolved analytically in Section 3. In Section 4 we release some restrictive assumptions and present the results of a numerical evaluation of biodiversity as well as a description 
of the decision rules. We conclude in the last section.

\section{A general model to evaluate biodiversity}

A species' value results from its production or use value. We define a pool of species by the condition that species in the pool are perfectly substitutable in their use. They are also costly to conserve and any loss of species is irreversible; we ignore the possible apparition of new species on the ground that it occurs on a longer time scale.

The decision-maker, call her 'society', benefits from a specific service that can be provided by each of the $n$ available species; since the species are perfectly substitutable, only one, the one which is most valuable at the time, is put into use at any time. The value $\tilde{v}_{i}$ of the service is inherent to species $i$. Current values $\tilde{v}_{i}$ are observable but future values are uncertain. For example, a zoo might have a spot for elephants. Two species of elephants exist: big elephants $i$ and smaller ones $j$ but at any time only one species can be shown. At times where big elephants are in demand $\left(\tilde{v}_{i}>\tilde{v}_{j}\right)$, big elephants will be exhibited by the zoo; when small elephants are fashionable $\left(\tilde{v}_{i}<\tilde{v}_{j}\right)$, small elephants will be shown. More realistically one may think of the main active principle in a medication as being potentially provided by several species, with only the currently preferred species being in use at any one time, perhaps because the principle is cheaper to extract from that species, or because its location is more favorable. However, should the situation change and another species become preferable, substitution is costless and the newly preferred species becomes the one used in preparing the medication.

Information on species evolve over time, making future values uncertain. We assume that the value $\tilde{v}_{i}$ of species $i$ follows a geometric Brownian motion, with constant drift $\alpha_{i}$ and variance $\sigma_{i}^{2} d t$ :

$$
d \tilde{v}_{i}=\alpha_{i} \tilde{v}_{i} d t+\sigma_{i} \tilde{v}_{i} d z_{i}
$$

where $d z_{i}$ is the increment of a Wiener process. Assuming a Brownian geometric motion is not simply a matter of convenience here, but probably the best simple alternative: 
the value cannot be negative and, as with wealth or with future knowledge, there is no particular force that would maintain it at, or take it back to, any particular level. ${ }^{3}$ In general some sources of uncertainty over future values may be common to species; for example if a medication becomes highly valued, all the species providing its main principle will probably increase in value. We call $\rho_{i j}$ the correlation coefficient: $E\left(d z_{i} d z_{j}\right)=\rho_{i j} d t$.

If the decision-maker wants to keep open the opport unity of using biodiversity assets for present or future use, she must devote resources to their maintenance. We model conservation expenditures as a continuous non stochastic cost $C\left(\tilde{v}_{i}\right)$ that can be interrupted at any time; if the expenditure is interrupted, the species disappears irreversibly. We call $v_{i} \equiv \tilde{v}_{i}$ the value of species $i$ when it is in existence, and we set $v_{i}=0$ when the species is extinct, with $C(0)=0$. Thus, at any time $t$, there are $n(t) \leq N$ existing: species whose value is strictly positive, and $N-n(t)$ extinct species whose value is zero, where $n(t)$ and $N$ are integers and $N$ is the initial number of species.

At any instant, the decision-maker may decide to limit the diversity of the set of species, thereby reducing conservation costs and causing the irrevocable depletion of biodiversity. The decision to let a species disappear by cutting its conservation expenditure implies losing the option to make use of it in the future. This is an optimal stopping problem in continuous time with $n(t)$ stochastic state variables; $n(t)$ is determined by past conservation decisions. At all dates, the decision-maker compares the net expected value of preserving the $n(t)$ remaining species while using the most valuable one, to the expected value obtained if one or more of the $n(t)-1$ unexploited species is abandoned. Each state is described by a leading species $i(i \in\{1 \ldots n(t)\})$ and, $(n(t)-1)$ species $j$ $(j \neq i)$ whose survival status must be chosen.

The cumulated expected return from using species $i$ over an infinite time horizon is $E_{t} \int_{t}^{\infty} e^{-r(s-t)} v_{i}(s) d s$ where $r$ is a discount rate. Let $\bar{v}_{t}=\max \left\{v_{i}(t)\right\}$; since it is possible to switch species in such a way as to exploit the most valuable one at any time,

\footnotetext{
${ }^{3} \mathrm{~A}$ good comparison is wealth, whose level is not limited in its growth by such factors as, say, production costs, unlike the price of a good.
} 
the expected net present value from using the whole set of species is

$$
\begin{aligned}
& F\left(v_{1}(t), \ldots, v_{N}(t)\right)= \\
& \max _{I_{i}(t) \in\{\mathbf{0}, 1\}} E_{t}\left\{\int_{t}^{\infty} e^{-r(s-t)} \bar{v}(s) d s(s)-\sum_{k=1}^{N} \int_{t}^{\infty} e^{-r(s-t)} C\left(v_{i}(s)\right) d s \mid v_{i}\left(t^{+}\right)=I_{i}(t) v_{i}(t)\right\}
\end{aligned}
$$

where the second term on the right-hand side accounts for cumulative discounted costs of maintenance costs. The decision to let species $i$ disappear at date $t$ corresponds to setting $I_{i}(t)=0$; thereafter, $v_{i}(s), s>t$, remains equal to zero and so does the associated maintenance cost. Although, at any time $t$, the $I_{i}(t)$ vector has $N$ elements, the choice is only relevant in the case of non extinct species: when a species is already extinct, setting $I_{j}(t)=0$ or 1 does not make any difference since $v_{j}(s)$ remains equal to zero thereafter anyway.

Under symmetry $\left(\alpha_{i}=\alpha ; \sigma_{i}=\sigma\right)$ and perfect correlation $\left(\rho_{i j}=1\right)$, the problem reduces to the classic real options model (Fisher and Hanemann (1987), Henry (1974)). Indeed, the decision-maker would only consider preserving the initially dominant species. She does not expect any change in relative advantages between available species so that all species but the dominant one are valueless, implying that diversity is valueless. This is the context under which Simpson et al (1996) observe that perfect substitution annihilates diversity value: not only must perfect substitution be possible; the preferred species must also be the same forever.

The main focus of this work is on valuing biodiversity and determining the strength of conservation incentives when species are perfectly substitutable. To make the analysis tractable and rigorous, we first concentrate on a simplified model which admits an analytical solution. Then we release some of the simplifying assumptions and solve the new model by numerical methods. We find that the main intuitions of the simplified model carry out to the more general one. 


\section{A simplified two species homogenous model}

The range of available biodiversity components is narrowed to $N=2$. It is also assumed that the processes governing species are symmetrical; when the species are in existence,

$$
\frac{d v_{i}}{v_{i}}=\alpha d t+\sigma d z_{i}, i=1,2
$$

with $\rho_{12}=\rho$.

Furthermore, we assume that the cost $C_{i}$ of maintaining species $i$ is proportional to its use value $v_{i}: C_{i}=k v_{i}$ with $k<1$. At any time $t$ when both species exist, the decision maker exploits the dominant species $i\left(v_{i}>v_{j} ; i, j \in\{1,2\}\right)$ and receives a current net return $v_{i}-k v_{i}-k v_{j}$. Proportionality of conservation costs implies homogeneity of degree one of value functions, as we will verify below.

The decision-maker must decide whether to continue spending for the preservation of the currently unproductive species or to exercise the option to disinvest. If biodiversity is maintained, the decision-maker holds the option to change the species in use at any future time if the prevailing state of dominance is reversed. Note that with $k<1$, at least one species is always conserved; this is not so in the case with constant costs examined further below.

By symmetry the same value function applies whether species 1 or species 2 has been allowed to go extinct: $V\left(v_{2}(t)\right)=F\left(0, v_{2}(t)\right)\left(V\left(v_{1}(t)\right)=F\left(v_{1}(t), 0\right)\right)$ with:

$$
\begin{aligned}
V\left(v_{i}(t)\right) & =E_{t} \int_{t}^{\infty} e^{-r(s-t)}(1-k) v_{i}(s) d s \\
& =\left\{\begin{array}{l}
\frac{(1-k)}{r-\alpha} v_{i}(t) \text { if } r>\alpha \\
\infty \text { if } r \leq \alpha
\end{array}\right.
\end{aligned}
$$

We will focus on the case $r>\alpha$ to avoid tedious analyses of alternative cases.

When both species coexist, the expected net present value of cumulated payoffs $F\left(v_{1}, v_{2}\right)$ may be thought of as taking two alternative forms: $F_{1}\left(v_{1}, v_{2}\right)$, applying when

$v_{1} \geq v_{2} ;$ and $F_{2}\left(v_{1}, v_{2}\right)$, applying in the alternative case; reversals may happen several times during the period when both species coexist. During a time interval where $v_{1} \geq v_{2}$, 
species 1 is in use and both species are maintained so that

$$
\begin{aligned}
F_{1}\left(v_{1}, v_{2}\right)= & \left((1-k) v_{1}-k v_{2}\right) d t+E_{t}\left\{e^{-r(t+d t)} F_{1}\left(v_{1}+d v_{1}, v_{2}+d v_{2}\right)\right\} \\
& \text { subject to }(2), i=1,2
\end{aligned}
$$

The problem is symmetric, so we can solve (4) and treat the case where species 2 dominates by symmetry.

The Bellman equation is

$$
r F_{1}\left(v_{1}, v_{2}\right) d t=\left((1-k) v_{1}-k v_{2}\right) d t+E\left[d F_{1}\right]
$$

Fxpanding the expectation term in (5), using Ito's Lemma and substituting equation (2) for $d v_{1}$ and $d v_{2}$, we get the following second-order partial differential equation in $v_{1}$ and $v_{2}$.

$$
\begin{aligned}
\sigma^{2}\left(\frac{v_{1}^{2}}{2} \frac{\partial^{2} F_{1}}{\partial v_{1}^{2}}+\frac{v_{2}^{2}}{2} \frac{\partial^{2} F_{1}}{\partial v_{2}^{2}}+\right. & \left.\rho v_{1} v_{2} \frac{\partial^{2} F_{1}}{\partial v_{1} \partial v_{2}}\right) \\
& +\alpha\left(v_{1} \frac{\partial F_{1}}{\partial v_{1}}+v_{2} \frac{\partial F_{1}}{\partial v_{2}}\right)-r F_{1}+\left((1-k) v_{1}-k v_{2}\right)=0 .
\end{aligned}
$$

Equation (6) captures the dynamic relationship between the state variables $v_{1}$ and $v_{2}$ and must be satisfied by $F_{1}\left(v_{1}, v_{2}\right)$ when both species are in existence and species 1 dominates.

Equation (6) admits a particular solution $F_{1}^{p}\left(v_{1}, v_{2}\right)=\left(\frac{1-k}{r-\alpha} v_{1}-\frac{k}{r-\alpha} v_{2}\right)$ which is homogenous of degree 1 in $v_{1}$ and $v_{2}$. Complementary solutions $F_{1}^{c}\left(v_{1}, v_{2}\right)$ of the homogenous part of equation (6) must satisfy

$$
\sigma^{2}\left(\frac{v_{1}^{2}}{2} \frac{\partial^{2} F_{1}^{c}}{\partial v_{1}^{2}}+\frac{v_{2}^{2}}{2} \frac{\partial^{2} F_{1}^{c}}{\partial v_{2}^{2}}+\rho v_{1} v_{2} \frac{\partial^{2} F_{1}^{c}}{\partial v_{1} \partial v_{2}}\right)+\alpha\left(v_{1} \frac{\partial F_{1}^{c}}{\partial v_{1}}+v_{2} \frac{\partial F_{1}^{c}}{\partial v_{2}}\right)-r F_{1}^{c}=0
$$

Recalling the structure of the problem, an increase in $v_{1}$ and $v_{2}$ of the same proportion induces proportional increases in production returns and conservation costs. Hence, any general solution is homogenous of degree one in $v_{1}$ and $v_{2}$; Consequently, since general solutions must be the sum of a particular solution, homogenous here, and complementary solutions, any complementary solution must be homogenous of degree one as well. Thus 
$F_{1}^{c}$ may be written:

$$
F_{1}^{c}\left(v_{1}, v_{2}\right)=v_{2} g_{1}\left(V_{2}\right) \quad \text { with } \quad V_{2}=\frac{v_{1}}{v_{2}}
$$

It is clear that the decision rule depends on the ratio $\frac{v_{1}}{v_{2}}$ and is homogenous de degree zero. Equation (7) becomes:

$$
(1-\rho) \sigma^{2} V_{2}^{2} \frac{d^{2} g_{1}\left(V_{2}\right)}{d V_{2}^{2}}+(\alpha-r) g_{1}\left(V_{2}\right)=0
$$

Any solution of (8) is of the form $A_{1} V_{2}^{\beta_{1}}+A_{2} V_{2}^{\beta_{2}}$ where $A_{1}$ and $A_{2}$ are constants to be determined; the constants $\beta_{1}>1$ and $\beta_{2}<0$ are respectively the positive and the negative roots of the quadratic equation $\beta^{2}-\beta+\frac{\alpha-r}{(1-\rho) \sigma^{2}}=0^{4}$ :

$$
\beta_{i}=\frac{1}{2} \pm \sqrt{\frac{1}{4}+\frac{r-\alpha}{(1-\rho) \sigma^{2}}}
$$

Any complete solution for (6) is the sum of a particular solution and the complementary solution and can be written:

$$
\begin{aligned}
F_{1}\left(v_{1}, v_{2}\right) & =v_{2}\left(A_{1} V_{2}^{\beta_{1}}+A_{2} V_{2}^{\beta_{2}}\right)+v_{2}\left(\frac{1-k}{r-\alpha} V_{2}-\frac{k}{r-\alpha}\right) \text { with } V_{2}=\frac{v_{1}}{v_{2}} \\
& \equiv v_{2} G_{1}\left(V_{2}\right)
\end{aligned}
$$

The second term between represents the expected net present value if the status quo is maintained forever: use and maintain species 1 for ever as in (3) and maintain species 2 forever at an expected cost of $\frac{k}{r-\alpha} v_{2}$. It follows that the other term must account for the two options available when species 1 is in use: switch to species 2 when $v_{2}$ overtakes $v_{1}$; and abandon species 2 when $v_{2}$ becomes low enough relative to $v_{1}$.

Turning now to situations where species 2 is dominant $\left(v_{2}>v_{1}\right)$ and both species are in existence, all variables and functions may be defined by symmetry, and the same properties hold: $V_{1}=\frac{v_{2}}{v_{1}}=\frac{1}{V_{2}}$ and the linearly homogeneous value function $F_{2}$ is

$$
\begin{aligned}
F_{2}\left(v_{2}, v_{1}\right) & =v_{1}\left(A_{1} V_{1}^{\beta_{1}}+A_{2} V_{1}^{\beta_{2}}\right)+v_{1}\left(\frac{1-k}{r-\alpha} V_{1}-\frac{k}{r-\alpha}\right) \equiv v_{1} G_{1}\left(V_{1}\right) \\
& =v_{2}\left(A_{1} V_{2}^{1-\beta_{1}}+A_{2} V_{2}^{1-\beta_{2}}\right)+v_{2}\left(\frac{1-k}{r-\alpha}-\frac{k}{r-\alpha} V_{2}\right)
\end{aligned}
$$

\footnotetext{
${ }^{4}$ Replace $g_{1}(v)$ by its general solution $A v^{\beta}$ in (8) to obtain a quadratic equation in $\beta$.
} 
For a complete description of the solution, we need the values of $A_{1}$ and $A_{2}$, as well as the threshold values of $V_{2}, V_{2}^{*}$, which triggers the abandonment of species 2 (by symmetry the threshold value of $V_{1}$ is $\left.\frac{1}{V_{2}^{*}}\right)$. We also need to characterize the transition between situations where one species is dominant and situations where the other species is dominant.

\subsection{Abandonment rules and dominance changes}

When $v_{i}>v_{j}$, conservation of species $j$ is optimal if $v_{j}$ is larger than the critical boundary $v_{j}^{*}\left(v_{i}\right)$. This frontier separates a waiting region (biodiversity conservation) from an exercise region (biodiversity loss). As was noted above, the decision depends only on the ratio $V_{j}=\frac{v_{i}}{v_{j}}: v_{j}^{*}\left(v_{i}\right)$ must be a straight line starting from the origin. Thus, for the abandonment of species $2, v_{2}^{*}\left(v_{1}\right) \equiv V_{2}^{*} v_{1}$, where the constant $V_{2}^{*}$ denotes the critical line slope. Similarly, for the abandonment of species $1, v_{1}^{*}\left(v_{2}\right) \equiv V_{2}^{*} v_{2}$, or $v_{2}^{*}\left(v_{1}\right)=\frac{1}{V_{2}^{*}} v_{1}$.

On the critical frontier the value function $F_{i}\left(v_{i}, v_{j}\right)$ must satisfy the value-matching: condition and the smooth-pasting condition

$$
\begin{aligned}
F_{i}\left(v_{i}, v_{j}\right) & =V\left(v_{i}\right) \text { when } v_{i}=v_{j}^{*^{-1}}\left(v_{j}\right) \\
\frac{\partial F_{i}\left(v_{i}, v_{j}\right)}{\partial v_{i}} & =\frac{\partial V\left(v_{i}\right)}{\partial v_{i}} \text { when } v_{i}=v_{j}^{*^{-1}}\left(v_{j}\right) .
\end{aligned}
$$

Condition (12) says that on $v_{j}^{*}\left(v_{i}\right)$ the decision-maker is indifferent between conserving species $j$ and losing it; condition (13) imposes the equality of marginal (in $v_{i}$ ) changes in the continuation value and the stopping value when $v_{j}=v_{j}^{*}\left(v_{i}\right)$.

For $i=1$, substituting (9) for $F_{1}\left(v_{1}, v_{2}\right)$, and (3) for $V\left(v_{2}\right)$ in $(12)$ gives:

$$
A_{1} V_{2}^{*^{\beta_{1}}}+A_{2} V_{2}^{*^{\beta_{2}}}-\frac{k}{r-\alpha}=0
$$

Substituting for the same functions in (13) after deriving with respect to $v_{1}$ gives:

$$
A_{1} \beta_{1} V_{2}^{*^{\beta_{1}}}+A_{2} \beta_{2} V_{2}^{*^{\beta_{2}}}=0
$$

For $i=2$, similar manipulations using (11) give:

$$
A_{1} \beta_{1} V_{2}^{*^{-\beta_{1}}}+A_{2} \beta_{2} V_{2}^{*^{-\beta_{2}}}=0
$$


Since $V_{1}=\frac{1}{V_{2}}$, (16), concerning the abandonment of species 2, is analogous to (15), for the abandonment of species 1 , when $V_{1}^{*}$ is substituted for $V_{2}^{*}$.

Finally, the dominant species changes whenever the line $v_{1}=v_{2}$ is crossed by the pair $\left(v_{1}, v_{2}\right)$. By symmetry, when $v_{1}=v_{2}$, the functions $F_{1}\left(v_{1}, v_{2}\right)$ and $F_{2}\left(v_{2}, v_{1}\right)$ must be equal and have the same derivatives with respect to $v_{1}$ and $v_{2}$ respectively. Using (10) and (11), it follows after some manipulations that, at $V_{1}=V_{2}=1, G_{1}(1)=G_{1}(1)$ and $\frac{\partial G_{1}(1)}{\partial V_{2}}=\frac{\partial G_{1}(1)}{\partial V_{1}}$. Thus these two conditions do not provide any additional information.

To recapitulate, the abandonment conditions imply three equations, (14), (15), and (16), in the three variables, $A_{1}, A_{2}$, and $V_{2}^{*}$. This solves the problem implicitly. The constants $A_{1}$ and $A_{2}$ are positive (otherwise (14) and (15) could not be true simultanously). The solution is illustrated in Figure 1 for $r=.08 ; C_{i}=\frac{1}{4} v_{i} ; \alpha=0.04 ; \sigma^{2}=0.02$; and $\rho=0$. The graph shows the abandonment values $v_{2}^{*}\left(v_{1}\right) \equiv V_{2}^{*} v_{1}$ for species 2 in the $\left(v_{1}, v_{2}\right)$ plane; a similar locus $v_{1}^{*-1}\left(v_{2}\right)$ gives the critical value $v_{1}$ below which species 1 is to be abandoned. The conservation region is bounded by these two linear critical frontiers. When both species exist, species 1 is in use and for each $\left(v_{1}, v_{2}\right)$ pair under the bisecting line, while species 2 is in use for pairs above the bisecting line.

In the deterministic case, the unexploited species is abandoned without any delay; the critical lines merge and the conservation area vanishes. Uncertainty makes any irreversible biodiversity loss costly, which creates a value to waiting and conserving despite the fact that the species are perfect substitutes.

At its maximum, reached on the bisecting line, the option value represents $14 \%$ of the total value. The conservation area represents almost $53 \%$ of the total surface of the graph, which means that for more than half the possible realizations it is desirable to preserve biodiversity. This motivation for conservation would be absent were the species not substitutable.

It is also intuitively clear and simple to show that the value of biodiversity is decreasing in $k$ and increasing in $\sigma$. Greater $k$ means higher costs: it is more expensive to maintain biodiversity for a possible future use. An increase in $k$ reduces the conservation 


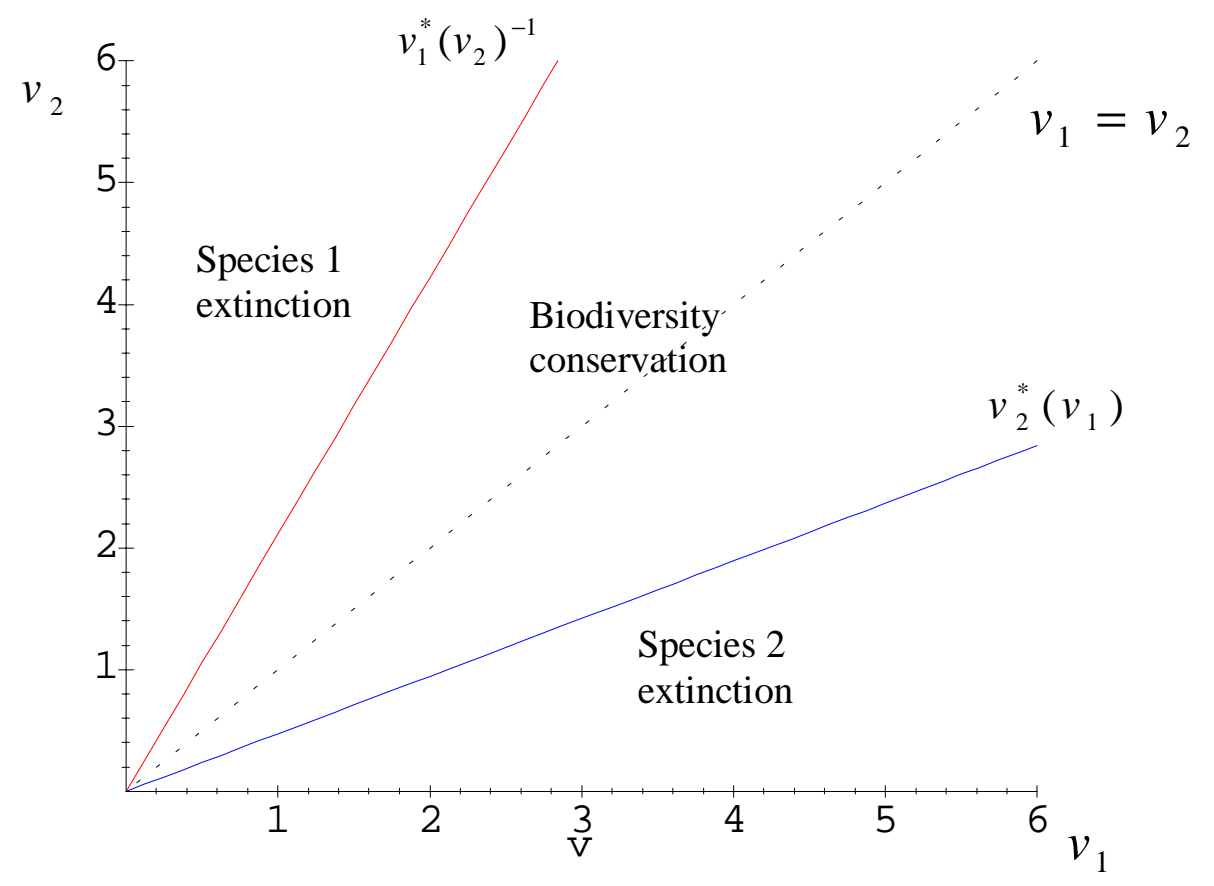

Figure 1: Conservation decision: critical frontiers

area in Figure 1.

On the other hand, with greater uncertainty (higher $\sigma$ ), the gap between the critical frontiers is larger; the critical abandonment values are less severe. This can be shown using proofs of similar impacts of volatility that appear repeatedly in the literature (see Dixit and Pindyck, 1994). For example, when the variable under scrutiny is the decision to invest, the value of the option is governed by a differential equation which is formally identical to (8). It is shown that the investment threshold is lower and the value of the option is higher when volatility is higher. In equation (8), the variable under investigation is not the investment threshold but the relative species value $V_{2}$. The threshold value $V_{2}^{*}$ which triggers the abandonment of species 2 is thus lower when volatility is higher, which means that the $v_{2}^{*}\left(v_{1}\right)$ curve has a lower slope in Figure 1. By symmetry, the curve corresponding to the abandonment of species 1 has a higher slope, so that the biodiversity conservation zone is larger when volatility is higher. The intuition for this result is also clear: when volatility is higher, the probability of a 
reversal in species dominance is higher; in order to avoid regretting the abandonment of a species, it is then better to require more pronounced a dominance before letting the species disappear.

The role of value correlation is also crucial and complementary. A visual inspection of (8) indicates that $(1-\rho)$ multiplies $\sigma^{2}$; thus a rise in $\rho$ has the same impact as a drop in $\sigma$. When species values tend to move in opposite directions $(\rho<0)$, the impact of volatility is amplified; indeed reversals in species dominance are more likely when the correlation is negative, so that abandonment is riskier, which calls for a larger conservation zone. On the contrary, when $\rho=1$, the conservation zone disappears altogether because it is certain that no reversal will ever occur.

\subsection{The marginal value of biodiversity}

Simpson, Sedjo and Reid (1996) find that the value of the marginal species is decreasing with the number of available species. The richer biodiversity, the lower the contribution of a given species to total value. The same result obtains here. In the absence of biodiversity, the net use value $V\left(v_{i}\right)$ of the subsisting species is given by equation $(3)$. The marginal value of diversity is the additional value achieved if the second species is in existence, tough unexploited. When the marginal species is species 2, its marginal value is ${ }^{5}$

$$
V_{m 2}\left(v_{1}, v_{2}\right)=F_{1}\left(v_{1}, v_{2}\right)-V\left(v_{1}\right), v_{2}^{*}\left(v_{1}\right)<v_{2} \leq v_{1}
$$

Figure 2 gives the values of species $j$ in two circumstances: in the absence of biodiversity, when $j$ is the sole existing species; and in the presence of biodiversity when $j$ is not in use although $v_{1}=v_{2}$. The figure makes it plain that, although species 1 and 2 are identical and could be substituted for each other at no cost, maintaining two of them provides less additional value, $V_{m j}$, than maintaining only one, $V$. Thus in the situation most favorable to the marginal species $j$, that is when $v_{i}=v_{j}$, the marginal species has less

\footnotetext{
${ }^{5}$ Marginal value is defined as net of maintenance cost.
} 
value than the other species; in less favorable circumstances not represented in Figure 2, when $v_{j}<v_{i}$, the relative value of the marginal species is even lower; when $v_{j}=v_{j}^{*}\left(v_{i}\right)$, the marginal value of species $j$ is zero.

It is shown in the Appendix that $V_{m 2}\left(v_{1}, v_{2}\right)$ is rising and convex in $v_{2}$. This clarifies the notion of marginal value. On one hand, the contribution of the marginal species to the total value of the pool is lower than the contribution of other species; this property borders triviality as this is precisely the way species were ranked in the first place. On the second hand, within the interval over which a species is marginal, its marginal value is rising and convex. This property is little known in the context of biodiversity although convexity is known to be arising in presence of real options.

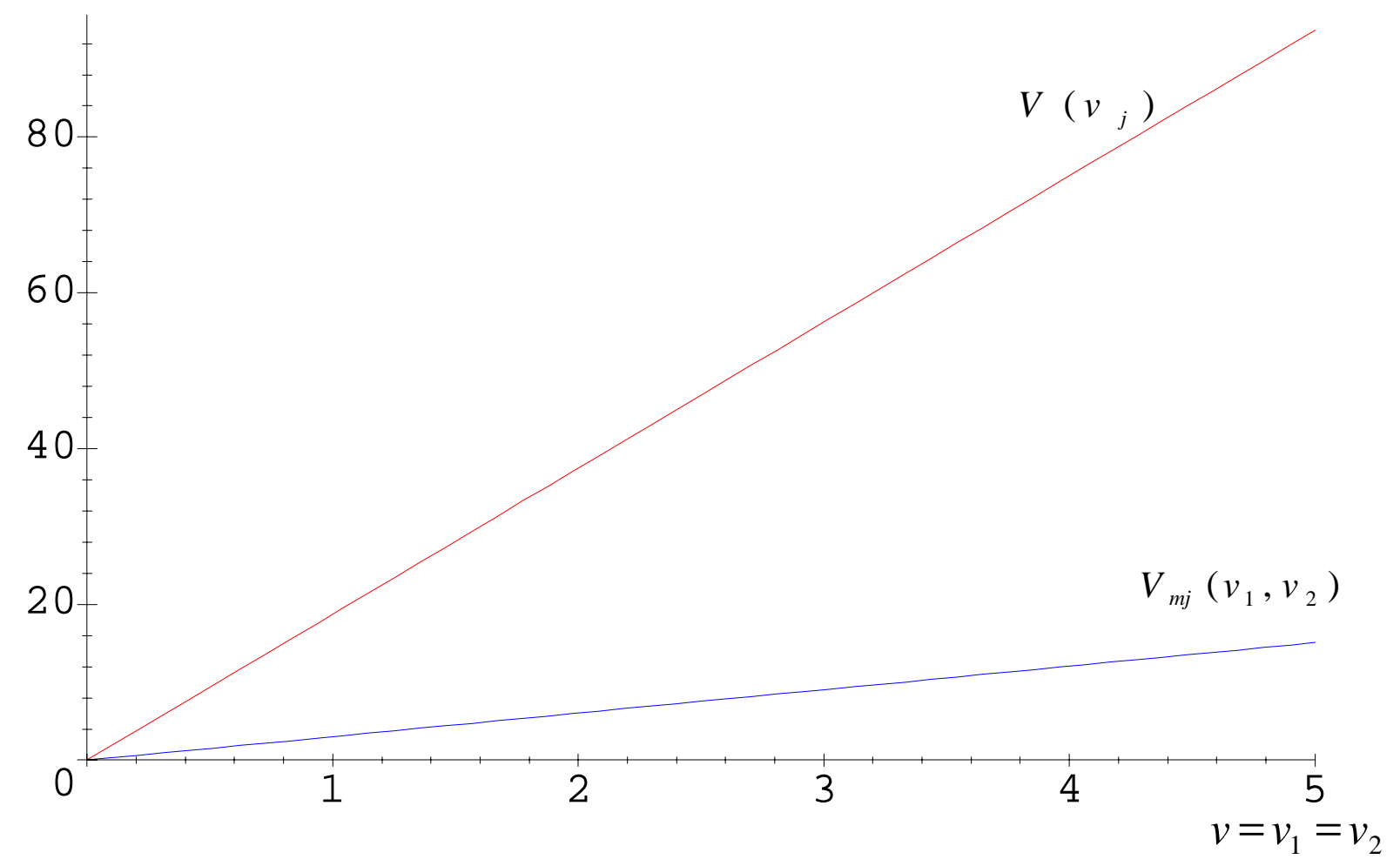

Figure 2: Marginal species values

It is simple to see that these results also obtain when the number of species exceeds two, and do not rely on the homogeneity of the value function in surviving species. 
Consider Problem (1) when three species are in existence, at a date when it is optimal to let one of them disappear, say species 3. Suppose without loss of generality that species 1 is in use; then, by definition of the maximization in $(1), F\left(v_{1}, v_{2}, v_{3}\right)=F\left(v_{1}, v_{2}, 0\right)$ and $F\left(v_{1}, 0, v_{3}\right)<F\left(v_{1}, v_{2}, 0\right)$. It follows that the marginal value of species 3 is zero, $V_{m 3}\left(v_{1}, v_{2}, v_{3}\right) \equiv F\left(v_{1}, v_{2}, v_{3}\right)-F\left(v_{1}, v_{2}, 0\right)=0$, while the marginal value of species 2 is positive: $V_{m 2}\left(v_{1}, v_{2}, v_{3}\right) \equiv F\left(v_{1}, v_{2}, v_{3}\right)-F\left(v_{1}, 0, v_{3}\right)>0$. Similar arguments can be constructed at dates other than abandonment dates and for any number of existing species. Unused species play the role of insurance against a drop in the value of the species in use. The more numerous unused species, the less valuable the extra insurance coverage provided by the marginal species.

\section{A non-homogenous model: numerical resolution}

The homogeneity of the value functions enabled us to derive an algebraic solution for the model. This property obtains under the assumption that conservation costs are proportional to the use value of the species. This proportionality rules out total extinction because the cost of maintaining the last species is always smaller than its value, however small. In many circumstances, it is more realistic to assume the conservation cost to be independent of species value.

In what follows, we assume a constant cost $C$ for maintaining a species $^{6}$. As a result the current net utility derived from exploiting a species may be negative if its use value is sufficiently low: the decision-maker must consider the option of abandoning: the sole subsisting species altogether. All other assumptions of the previous section are maintained; unless otherwise mentioned, the notation is the same.

We will first determine the value function and the optimal disinvestment rule when there is only one surviving species. Next, we will evaluate biodiversity numerically and characterize the conservation decisions in presence of two species. It can be anticipated

\footnotetext{
${ }^{6}$ It could also be assumed that $C\left(v_{i}\right)=C+k v_{i}$. For example, protection from poaching may become costlier as the value of the species increases. Our methodology can be adapted to such a possibility.
} 
that the critical frontiers are not linear since the value functions are not homogenous.

\subsection{The last surviving species}

The value of a single surviving species is the expected cumulated discounted value of exploiting and maintaining the species until, possibly, it is allowed to disappear. Since $N=1$, expression (1) reduces to

$V\left(v_{i}(t)\right)=\max _{I_{i}(t) \in\{\mathbf{0}, 1\}} E_{t}\left\{\int_{t}^{\infty} e^{-r(s-t)} v_{i}(s) d s(s)-\int_{t}^{\infty} e^{-r(s-t)} C d s \mid v_{i}\left(t^{+}\right)=I_{i}(t) v_{i}(t)\right\}$

or

$$
V\left(v_{i}\right)=D v_{i}^{\beta_{2}}+\frac{v_{i}}{r-\alpha}-\frac{C}{r}
$$

where

$$
D=\frac{-1}{\beta_{2}(r-\alpha)} v_{i}^{*^{\left(1-\beta_{2}\right)}}>0
$$

and the abandonment rule takes the form of a critical value $v_{i}^{*}$ such that it is optimal to let species $i$ disappear once $v_{i}<v_{i}^{*}$ :

$$
v_{i}^{*}=\frac{\beta_{2}}{\beta_{2}-1} \frac{(r-\alpha) C}{r} .
$$

At $v_{i}^{*}$, since $\frac{\beta_{2}}{\beta_{2}-1} \frac{(r-\alpha)}{r}<1$, exploitation returns do not cover conservation costs. This is the usual result of the option value model applied to the problem of abandonment (Brennan and Schwartz (1985); Dixit (1989)). In the abandonment zone, preservation costs are high relative to current and expected returns. The probability that the value of the species will recover is so low that giving up the possibility of profitable use in the future is a better decision than exposure to heavier losses. In an unfavorable environment, complete extinction is desirable. 


\subsection{Biodiversity}

For any number of species above one, the Bellman equation analogous to (5) is a partial differential equation that cannot be solved analytically. We describe the numerical solution to the problem when two species are in existence. Rather than solving the Bellman equation, we compute a discrete version of the value function $F\left(v_{1}, v_{2}\right)$ directly, using a binomial approximation of the value processes (2) for $\sigma=0.2, \alpha=0.04, r=0.08$ and $C=4$.

Expression (18) defines the value function into which $F\left(v_{1}, v_{2}\right)$ is transformed when one of the two species is abandoned. Suppose that $v_{1}>v_{2}$, so that the decision to take is whether of not to abandon species 2 ; then, in discrete time,

$$
F_{1}\left(v_{1}, v_{2}\right)=\max _{I_{2} \in\{0,1\}} E_{t}\left\{\frac{1}{1+\mu} V\left(v_{1}\right) ; \frac{1}{1+\mu} F_{1}\left(v_{1}, v_{2}\right)\right\}
$$

where $\mu$ is the discount rate applying over the relevant time interval. The difficulty in the above maximization is that, while the abandonment alternative is known to yield $V\left(v_{1}\right)$, continuing preservation yields $F_{1}$, which is unknown. We obtain $F_{1}$ by successive iterations, each iterations yielding an improvement over the previous approximation $F_{1}^{a}\left(v_{1}, v_{2}\right)$. The process begins at $a=0$ and is terminated when the improvement becomes arbitrarily small. The initial approximation exploits the property that $F_{1}\left(v_{1}, v_{2}\right) \geq V\left(v_{1}\right)$; thus we set $F_{1}^{0}\left(v_{1}, v_{2}\right)=V\left(v_{1}\right)$ for a set $S$ of possible values of $\left(v_{1}, v_{2}\right)$ generated by the binomial approximation of the $v_{i}$ processes. Using that approximation for $F_{1}$ on the right-hand side of $(20)$, it is possible to compute the expected values and to solve the maximization problem. This generates a value for the left-hand side, $F_{1}^{1}\left(v_{1}, v_{2}\right)$ which is in its turn, used as a new, improved, approximation. Precisely the following formula is used repeatedly starting with $a=0$ :

$$
F_{1}^{a+1}\left(v_{1}, v_{2}\right)=\max _{I_{2} \in\{0,1\}} E_{t}\left\{\frac{1}{1+\mu} V\left(v_{1}\right) ; \frac{1}{1+\mu} F_{1}^{a}\left(v_{1}, v_{2}\right)\right\} .
$$

The solution $F_{1}^{a+1}$ becomes the new approximation to be used on the right-hand side in the next step, and the process is interrupted when the new function is arbitrarily 


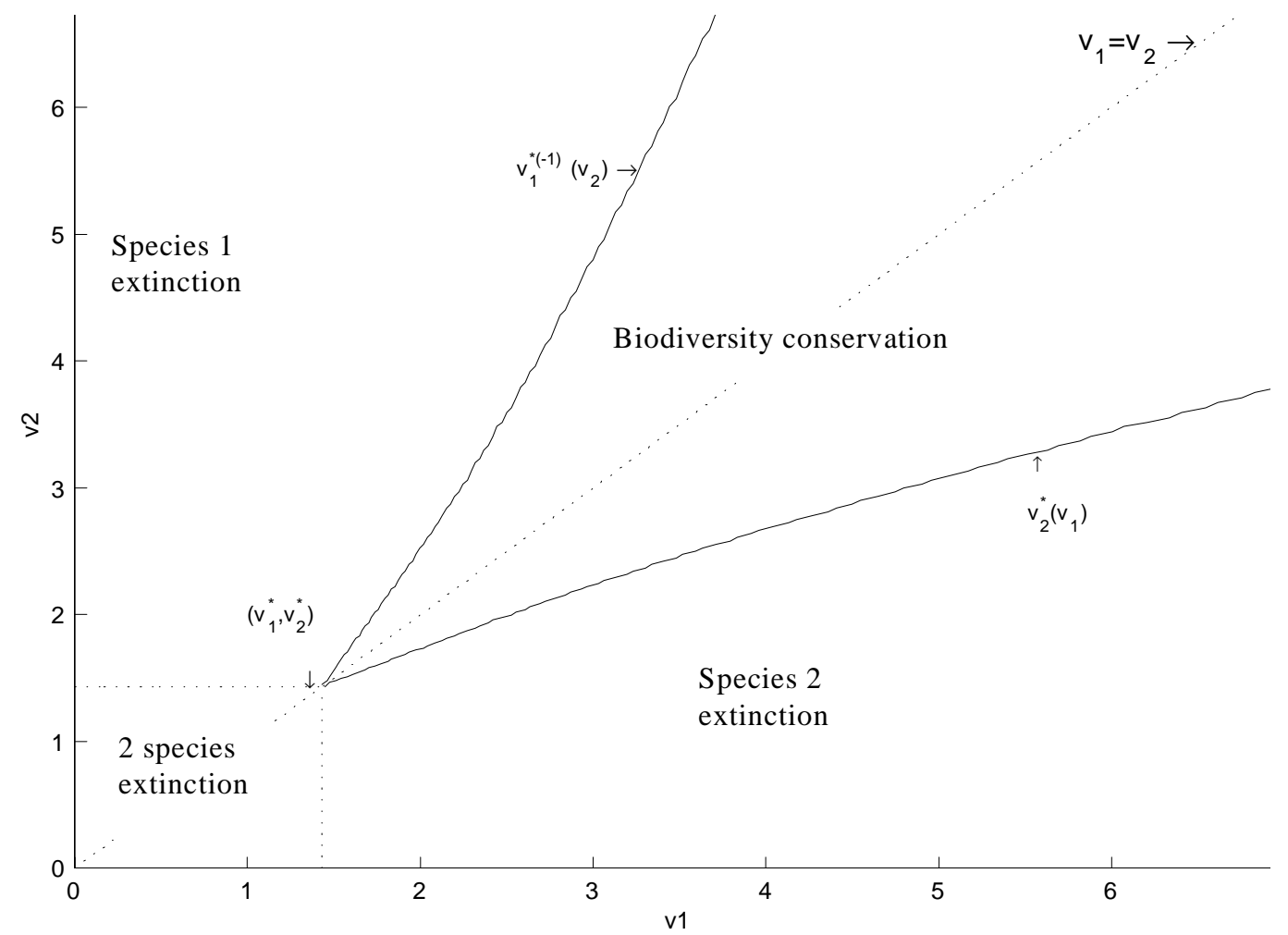

Figure 3: Conservation decision: critical frontiers

close to the old one for all values of $\left(v_{1}, v_{2}\right)$ in $S$. The function $F_{2}\left(v_{1}, v_{2}\right), v_{1}<v_{2}$, is generated in the same fashion.

As before, the solution can be described by the critical frontiers $v_{1}^{*}\left(v_{2}\right)$ and $v_{2}^{*}\left(v_{1}\right)$ in the $\left(v_{1}, v_{2}\right)$ plane. The curve $v_{1}^{*}\left(v_{2}\right)$ (respectively $v_{1}^{*}\left(v_{2}\right)$ ) represents $\left(v_{1}, v_{2}\right)$ pairs at which a rise in $v_{2}$ (a rise in $v_{1}$ ) cause the solution to the maximization in (20) to switch from conservation $\left(I_{i}\left(v_{1}, v_{2}\right)=1\right)$ to abandonment $\left(I_{i}\left(v_{1}, v_{2}\right)=0\right)$. The curves origin from a common point $\left(v_{1}^{*}=v^{*}, v_{2}^{*}=v^{*}\right)$ on the bisecting line, that corresponds to the abandonment thresholds defined by (19) for each species in the absence of diversity. For all pairs $\left(v_{1}, v_{2}\right)$ between the two curves, biodiversity is preserved. When both $v_{1}$ and $v_{2}$ exceed $v^{*}$ and $v_{j} \leq v_{j}^{*}\left(v_{i}\right)$ it is optimal to abandon species $j$, while keeping species $i$ in use; otherwise, conservation is optimal.

Along the critical boundary $v_{j}^{*}\left(v_{i}\right)$, the value of $v_{j}$ relative to $v_{i}$ is decreasing: when $v_{i}$ is close to $v^{*}$, a small dominance of species $i$ is sufficient to justify abandoning species 
$j$; when $v_{i}$ is high, it must dominate more definitely if species $j$ is to be abandoned. This happens because the expected loss becomes high relative to the cost saving as values become high; any mistake would be costly and mistakes are avoided by attributing a higher value to the abandonment option. A higher option value combined with unchanged conservation costs make conservation incentives stronger.

The value of the biological pool has two components. On the one hand, a higher value of the unexploited species $v_{j}$ brings the pair $\left(v_{1}, v_{2}\right)$ closer to equality. It is then more likely that the option to substitute species in use will be exercised rather than the option to reduce diversity; this is a source of value for the pool of species through its biodiversity component. On the other hand, if it is the value of the species in use that rises, the pair $\left(v_{1}, v_{2}\right)$ gets closer to the critical abandonment region; total value rises, but the value of biodiversity diminishes.

Figure 4 compares the conservation rules under proportional costs (previous section) and under constant costs. At low use values, conservation is more likely and total disappearance is ruled out, with proportional costs; with constant costs, conservation is more likely when use values are high.

\subsection{Uncertainty and value correlation}

A rise in uncertainty over future use values affects the conservation decision in two ways. First, the critical threshold $v^{*}$ for the conservation of the last surviving species diminishes. This is the standard option value result whereby the option to preserve and exploit a single available resource gains value when volatility rises, which makes disinvestment less attractive. Second, the biodiversity conservation region is larger because, for any $\left(v_{1}, v_{2}\right)$ pair, higher volatility means that substitution of the currently used species by the unused one is more likely. In Figure 3, the combination of these two effects of increased volatility is that the point $\left(v_{1}^{*}, v_{2}^{*}\right)$, from which the abandonment loci originate is shifted to the South-West, and that the abandonment loci make more open an angle than at lower volatility levels. 


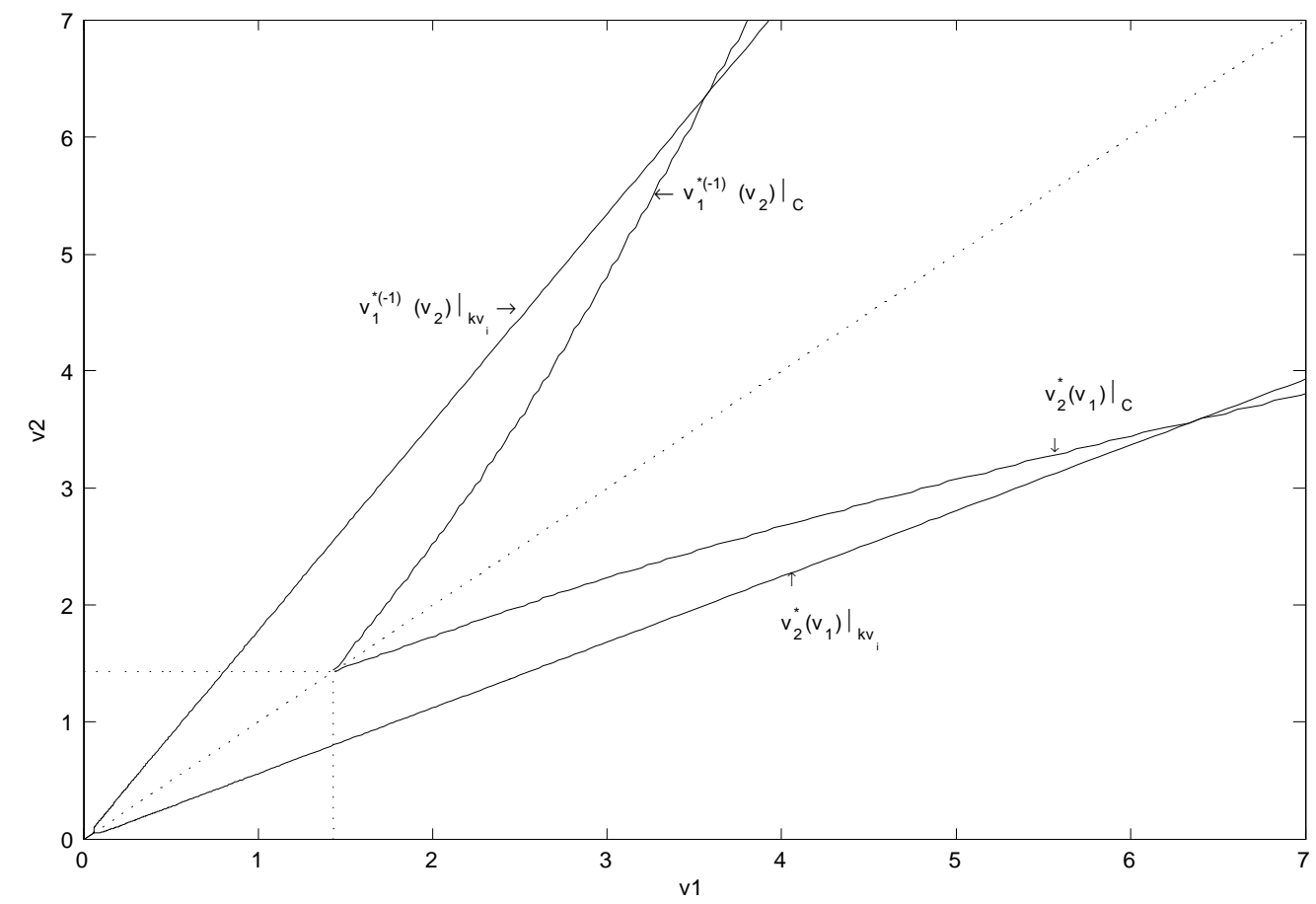

Figure 4: Decision rules for constant, and for proportional, conservation cost

The correlation in species' use values qualifies the effect of volatility. In the absence of uncertainty, the abandonment loci coincide and, although conservation of one species may be desirable, biodiversity is never optimal; the coefficient of correlation is meaningless since species values do not change. Under uncertainty, a positive correlation $\left(\rho_{12}>0\right)$ indicates that the values tend to move together; an increase in the value of one species does not imply that relative values change much, so that the probability of substitution is not very sensitive to value changes. With perfect positive correlation, the dominant species will remain dominant forever so that biodiversity has no value; it is always optimal to abandon the unused species, and the problem of conservation reduces to a standard one-variable real-options problem of the type already investigated in the environment literature.

On the contrary a negative correlation $\left(\rho_{12}<0\right)$ tends to amplify changes in relative values and the substitution probability. For any $\left(v_{1}, v_{2}\right)$ pair, the probability that the pair will cross the bisecting line and make substitution optimal over a given time interval 


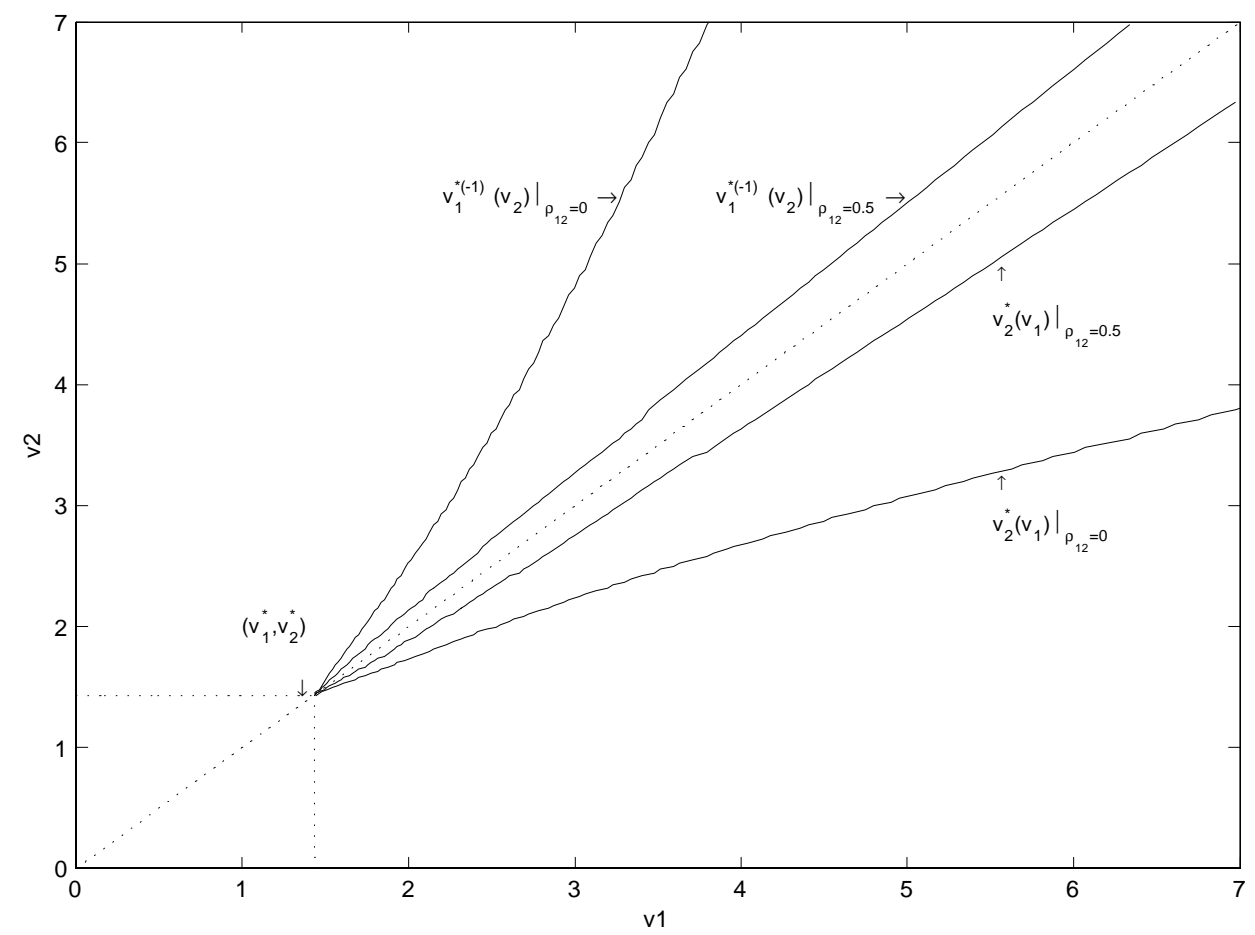

Figure 5: Effect of correlation on conservation

is higher so that abandoning the unused species is more likely to be a mistake than if $\rho_{12}$ was positive. As a result, the optimal abandonment loci make a wider angle, the lower the correlation coefficient, as shown in Figure 5.

\section{Discussion and conclusion}

The numerical solution procedure that we have used for the case of two species can be generalized to any higher number of species, yielding, for each number of species, the value of the marginal species, the abandonment rule, and the total value of the biological pool under investigation.

As illustrated for two species, the extension procedure requires establishing the value of holding $n-1$ species before that of holding $n$ species. It also requires knowing which species is the marginal one, i.e. the candidate for abandonment; when the processes governing species values are symmetric, the marginal species is the lowest-valued species; 
with more general processes, this may have to be verified numerically. In any case, the value of holding $n$ species is bounded below by the value of holding $n-1$ species, which provides a first approximation for the former. This first approximation can be improved upon by solving the $n$-species version of (20) repeatedly until the remaining error is small enough to be neglected. In the last iteration, the set of $v_{i}$ values at which a drop in the value of the marginal species leads to a switch from preservation to abandonment is defined as the abandonment locus for that species.

In existing analyses of species substitutability, it is argued that, if species are perfect substitutes, all species but the species in use are valueless because they are redundant. We have shown that, on the contrary, the fact that species can be substituted for one another gives value to biodiversity: an unused species derives value from the fact that it might, in the future, be in a better position to provide the same product or service as the one currently in use. This result is intuitively obvious in a real options context; however it can only be made formal within a several-species analysis, which has not been provided sofar in the resource literature.

Besides making the concept of decreasing marginal species value precise in this biodiversity context, we have shown, in the two-species homogenous model, that increased volatility raises biodiversity value and that a positive correlation between species values reduces the value of both the pool of species and biodiversity. Intuitive reasoning, and the computations made in the non homogenous case, lead us to conjecture that the same results hold for any number of species.

The second result, a negative relationship between the value of a species and the correlation of its value with that of other species, is reminiscent of the Beta of a financial asset. Just like an asset with a negative Beta derives additional value from the fact that it can provide insurance against fluctuations in the market portfolio, a species whose value tends to move in the opposite direction as the species in use derives additional value from its higher probability of being available for substitution if the value of the species in use diminishes.

In fact there is also an analogy between the single-asset, Mean-variance model and 
the single-asset, real-options model on one hand, and between the several-assets CAPM model and the many-species real-options model on the other hand. In the first two instances volatility is what matters; the value of a financial asset is lower, the higher its variance. In the second two instances the correlation between assets is just as important as their volatility; a low beta, or a low coefficient of correlation between species values, improves the ability of an asset (whether a species or a financial asset) to be used as insurance, thus giving it additional value.

Yet the analogy is not total. In real option models, irreversibility creates convexity in value, which explains why increased volatility means increased values, while volatility and expected return are substitutes in most financial management situations. An asset negatively correlated with the market derives value from the fact that it can be used to limit risk. A species whose value is negatively correlated with that of its substitutes derives its value from the fact that it can be used to seize the opportunities that may arise if it becomes dominant. Nature likes to play dices.

\section{Appendix: the marginal value of biodiversity}

Let species 2 be the marginal species: $v_{2}^{*}\left(v_{1}\right) \leq v_{1} \leq v_{1}$

$$
\begin{gathered}
V_{m 2}\left(v_{1}, v_{2}\right)=A_{1} v_{2}\left(\frac{v_{1}}{v_{2}}\right)^{\beta_{1}}+A_{2} v_{2}\left(\frac{v_{1}}{v_{2}}\right)^{\beta_{2}}-\frac{k}{r-\alpha} v_{2} \\
=A_{1} v_{2}^{1-\beta_{1}} v_{1}^{\beta_{1}}+A_{2} v_{2}^{1-\beta_{2}} v_{1}^{\beta_{2}}-\frac{k}{r-\alpha} v_{2} \\
\frac{\partial V_{m 2}}{\partial v_{2}}=\left(1-\beta_{1}\right) A_{1} v_{2}^{-\beta_{1}} v_{1}^{\beta_{1}}+\left(1-\beta_{2}\right) A_{2} v_{2}^{-\beta_{2}} v_{1}^{\beta_{2}}-\frac{k}{r-\alpha} \\
\frac{\partial^{2} V_{m 2}}{\partial v_{2}^{2}}=\beta_{1}\left(\beta_{1}-1\right) A_{1} v_{2}^{-\left(\beta_{1}+1\right)} v_{1}^{\beta_{1}}+\beta_{2}\left(\beta_{2}-1\right) A_{2} v_{2}^{-\left(\beta_{2}+1\right)} v_{1}^{\beta_{2}} .
\end{gathered}
$$

$A_{1}>0, A_{2}>0, \beta_{1}>1$, and $\beta_{2}<0 \Longrightarrow \frac{\partial^{2} V_{m 2}}{\partial v_{2}^{2}}>0 \Longrightarrow \frac{\partial V_{m 2}}{\partial v_{2}}$ is increasing in $v_{2}$. Also $\frac{\partial V_{m 2}}{\partial v_{2}}=0$ at $v_{2}=v_{2}^{*}\left(v_{1}\right)$ : this can be shown as follows. By smooth pasting (13) and value matching (12), at the abandonment of $2, \frac{k}{r-\alpha}=A_{1} V_{2}^{*^{\beta_{1}}}+A_{2} V_{2}^{*^{\beta_{2}}}$. Substituting into the expression for $\frac{\partial V_{m 2}}{\partial v_{2}}, \frac{\partial V_{m 2}}{\partial v_{2}}=-\beta_{1} A_{1} V_{2}^{\beta_{1}}-\beta_{2} A_{2} V_{2}{ }^{\beta_{2}}$, which is zero by (15). Since $\frac{\partial V_{m 2}}{\partial v_{2}}=0$ at $v_{2}=v_{2}^{*}\left(v_{1}\right)$ and rising in $v_{2}$ for any pair such that $v_{1}^{*}\left(v_{2}\right)<v_{1} \leq v_{2}, \quad \frac{\partial V_{m 2}}{\partial v_{2}}>0$ : 
Consequently, $V_{m 2}\left(v_{1}, v_{2}\right)$ is increasing in $v_{2}$ and reaches a maximum at $v_{1}=v_{2}$. By symmetry, a similar property applies to species 1 .

\section{References}

Arrow, K. J. and A. C. Fisher (1974) "Environmental Preservation, Uncertainty, and Irreversibility" Quarterly Journal of Economics 88, 312-19.

Boyle, Phelim P. (1988) "A Lattice Framework for Option Pricing with Two State Variables" Journal of Financial and Quantitative Analysis 23(1), 1-12.

Brennan, M. J. and E. S. Schwartz "Evaluating Natural Resource Investments" Jourmal of Business 58, 135-157.

Child, P.D., Ott, S.II. and A.J. Triantis (1998) "Capital Budgeting for Interrelated Projects: A Real Options Approach" Journal of Financial and Quantitative Analysis 33(3), 305-34.

Cox, John C., Ross, S. A. and Mark Rubinstein (1979) "Option Pricing: a Simplified Approach" Journal of Financial Economics 7, 229-63.

Dasgupta, P. (2000) "Valuing Biodiversity" in Encyclopedia of Biodiversity, ed.: S. Levin. New York: Academic Press.

Dixit, Avinash (1993) The Art of Smooth Pasting. CHUR: Harwood Academic Publishers.

Dixit, A. and R. S. Pindyck (1994) Investment under Uncertainty. Princeton: Princeton University Press.

Craft, A. B. and R. David Simpson (2001) "The Value of Biodiversity in Pharmaceutical Research with Differentiated Products" Environmental and Resource Economics 18(1), $1-17$.

Fisher Anthony A. and Michael W. Hanemann (1986) "Option Value and the Extinction of Species" Advances in Applied Microeconomics 4, 169-90.

Fisher Anthony. A. and Michael W. Hanemann (1987) "Quasi-Option Value: Some Misconceptions dispelled" Journal of Environmental economics and Management 14, 183190.

Fromm, Oliver (2000) "Ecological Structure and Functions of Biodiversity as Elements of Its Total Economic Value" Environmental and Resource Economics 16(3), 303-28.

Henry, Claude (1974) "Investment Decision Under Uncertainty: The Irreversibility Effect" American Economic Review 64(6), 1006-1012.

McDonald, R. and D. R. Siegel (1985) "Investment and The Valuation of Firms When There is an Option to Shut Down" International Economic Review 26, 331-349.

Moran, Dominic and Camill Bann (2000) "The Valuation of Biological Diversity for National Actions Plans and Strategies" Report prepared for the United Nations Environment Program. 
Norton, Bryan (1988) "Commodity, Amenity and Morality: the Limits of Quantification in Valuing Biodiversity" in Biodiversity, ed.: E.O.Wilson. Washington, D.C.: National Academy Press.

Pindyck, R. S. (1993) "Investment of Uncertain Cost" Journal of Financial Economics 34, 53-76.

Rausser, Gordon.C. and Arthur A. Small (2000) "Valuing Research Leads: Bioprospecting and the Conservation of Genetic Resources" Journal of political Economy 108(1), 173-206.

Simpson, R.David (1996) "Valuation of Biodiversity for Use in New Product Research in a Model of Sequential Search" Discussion Paper 96/27, Resource for the Future, Washington, D.C..

Simpson, R.David and Roger A.Sedjo (1996) "Investment in Biodiversity prospecting and Incentives for Conservation" Discussion Paper 96/14, Resource for the Future, Washington, D.C..

Simpson, R.David, Sedjo, Roger A. and John W. Reid (1996) "Valuing Biodiversity for Use in Pharmaceutical Research" Journal of political Economy 104(1), 163-85.

Swanson, Timothy (1994) "The Economics of Extinction Revisited and Revised: A Generalised Framework for the Analysis of the Problems of Endangered Species and Biodiversity Losses" Oxford Economic Papers 46, 800-21.

Triantis, A.J. and J. E. Hodder (1990) "Valuing Flexibility as a Complex Option" The Journal of Finance XLV, 549-65.

Trigeorgis, Lenos (1993) "The Nature of options Interactions and the Valuation of Investments with Multiple Real Options" Journal of Financial and Quantitative Analysis 28(1), 1-20.

Weitzman, Martin L. (1993) "What to preserve? An Application of Diversity Theory to Crane Conservation" Quarterly Journal of Economics 108(fev.), 157-83.

Weitzman, Martin L. (1998) "The Noah Ark Problem" Econometrica 66(6), 1279-98.

Wesseler, Justus (1999) "Temporal Uncertainty and Irreversibility: A Theoretical Framework for the Decision to Approve the Release of Transgenic Crops" in Transitions in Agbiotech: Economics of Strategy and Policy, ed. : William H.Lesser. 